\title{
Single-component white polymer light-emitting diode (WPLED) based on a binary tris-pyrazolonate-Sm-complex
}

\author{
Jiaxiang Liu ${ }^{a, 1}$, Wentao Li a,1 ${ }^{a}$ Baowen Wang a , Yani He a, Tiezheng Miao a , Xingqiang Lü a,b, ${ }^{*}$, Guorui Fu a, ${ }^{* *}$ \\ ${ }^{a}$ School of Chemical Engineering, Shaanxi Key Laboratory of Degradable Medical Materials, Northwest University, Xi'an, 710069, Shaanxi, China ${ }^{b}$ State Key Laboratory of \\ Structural Chemistry, Fujian Institute of Research on the Structure of Matter, Chinese Academy of Sciences, Fuzhou, 350002, Fujian, China
}

\section{ARTICLEINFO}

Keywords:

Organo-Sm ${ }^{3 \mathrm{p}}$-complex

Dichromatic doping system

Direct white-light

White polymer light-emitting diode

\section{A B S T R A C T}

Based on the doping of the binary tris-pyrazolate-Sm ${ }^{3 b}$ complex [Sm(tba-PMP) $\left.)_{3}\left(5-B r-2,2^{0}-b p y\right)\right]\left(\mathbf{1} ; \mathbf{5}-\mathbf{B r}-\mathbf{2}, \mathbf{2}^{\prime} \mathbf{b p y} \mathbf{1 / 4}\right.$ 5-bromo2,2 ${ }^{0}$-bipyridine and Htba-PMP $1 / 4$ 1-phenyl-3-methyl-4-(tert-butylacetyl)-5-pyrazolone)) with an efficient orange-light into the PVK (poly( $N$-vinylcarbazole) host, the obtained PVK@1 films exhibit the dichromatic color-tuning (white-light to purplish-pink and to pink) characters strictly relative to the $\mathrm{Sm}^{30}$ doping content and the $\lambda_{\text {ex }}$ wavelength. Further using the PVK@1 film (10:1; $\mathrm{wt} / \mathrm{wt})$ with the straightforward white-light $\left(\Phi_{\mathrm{PL}} 1 / 45.8 \%\right)$ as the emitting layer, its single-component solution-processed WPLED gives the electroluminescent performance ( $L^{\operatorname{Max}}$ of $157 \mathrm{~cd} / \mathrm{m}^{2}, \eta^{\operatorname{Max}}{ }_{\mathrm{c}}$ of $0.65 \mathrm{~cd} / \mathrm{A}$ and the white-light-emitting stability) satisfactory enough for portable full-color flat displays.

\section{Introduction}

Organo-L $\mathrm{n}^{3 \mathrm{~b}}$ complexes' luminescence has received considerable attention because of its $\mathrm{Ln}^{3 \mathrm{~b}}$-specific high color-purity phosphorescence [1,2] with theoretically $100 \%$ inner quantum efficiency, giving a particular opportunity to optoelectronic devices [2-6]. In this perspective, compared with concerted efforts to purity-monochromatic (typically $\mathrm{Tb}^{3 \mathrm{~b}}$-centered green-light [7-9], $\mathrm{Eu}^{3 \mathrm{~b}}$-centered red-light [10] or $\mathrm{Nd}^{3 \mathrm{~b}} / \mathrm{Yb}^{3 \mathrm{~b}} / \mathrm{Er}^{3 \mathrm{~b}}$-centered near-infrared-light [11]) organic/polymer light-emitting diodes (OLEDs/PLEDs), the realization of reliable panchromatic ones or white OLEDs/PLEDs (WOLEDs/WPLEDs) based on organo- $\mathrm{Ln}^{3 \mathrm{~b}}$ complexes significantly lags far behind [12-14], which should attribute to their complicated white-light integration during electric-driven process. Nonetheless, in contrast to non-organo- $\operatorname{Ln}^{3 b}$ counterparts $[15,16]$ strictly relative to ligand-fielded spectroscopic properties toward WOLEDs/WPLEDs, the $\mathrm{Ln}^{3 p}$-emissive visible color-primaries $[1,2]$ are advantageous of less perturbation from external stimulations (ligand/electricfield, $\mathrm{pH}$ or temperature, etc.). And clearly, from the viewpoint of white-light production, the dichromatic strategy should be more easily-gone [17] than the trichromatric- or tetrachromatric-integrated one with conceivably intractable energy transfers between multiple color-primaries.

As a matter of fact, contributing to the Laporte- and spin-allowed ligandcentered transition ( ${ }^{\circ} \mathrm{S} \rightarrow{ }^{1} \mathrm{~S}$ ) followed by the inter-system crossing (ISC; ${ }^{1} \mathrm{~S} \rightarrow$ $\left.{ }^{1} \mathrm{~T}\right)$ and the ${ }^{1} \mathrm{~T} \rightarrow \mathrm{Sm}^{3 \mathrm{~b} *}$ transfer $[18,19]$, the subsequent $\mathrm{Sm}^{3 \mathrm{~b}}$-centered orange-light hyper-sensitive at $650 \mathrm{~nm}\left({ }^{4} \mathrm{G}_{5 / 2} \rightarrow{ }^{6} \mathrm{H}_{9 / 2}\right.$ transition) can be efficiently sensitized from one certain organo- $\mathrm{Sm}^{3 b}$ complex. Further focusing on volatile organo-Sm ${ }^{3 p}$ complex by the vacuum-deposition [21-25] or doping of organo-Sm ${ }^{3 p}$ complex into a host (small-molecule $[26,27]$ or polymer $\left.[28,29]\right)$ by the solution-processed procedure, their OLEDs/PLEDs with the desirable
$\mathrm{Sm}^{3 \mathrm{~b}}$-centered orange-light have been envisioned. However, to the best of our knowledge, the generation of WOLEDs/WPLEDs using organo-Sm ${ }^{3 p}$ complex as the color-primary component, is very rare [30], despite the theoretically expectable white-light [17] capable of a blue-plus-orange combination. For example, as to the pioneering WOLED [30] fabricated with NPB[Sm(DBM) $)_{3}\left(\right.$ phen)] (NPB $\quad 1 / 4 \quad N, N^{0}-d i \quad$ (naphthalen-1-yl)- $N, N^{0}$-diphenyl-[1,1 $1_{-}$ biphenyl]-4,4-diamine, DBM $1 / 4$ dibenzoylmethane; phen $1 / 4 \quad 1,10-$ phenanthroline) co-deposited emitters, although its electroluminescent white-lights (CIE chromatic coordinates $x$ 1/4 $0.32-0.28, y \frac{1 / 4}{4} 0.28-0.33$ ) are stable and voltage-independent, the white-lights' integration is highly responsible with the unmanageable NPB-[Sm(DBM) $)_{3}$ (phen)] exciplex's colorcompensation. And more unfortunately, besides the vacuum-deposition highcost, its electroluminescent performance $\left(L^{\max } \mathrm{e}^{1 / 4} 142 \mathrm{~cd} / \mathrm{m}^{2}\right.$ and $\eta^{\max }{ }_{c}^{1 / 4} 0.17$ $\mathrm{cd} / \mathrm{A})$ is unsatisfactory, and even inferior to that $\left(L_{\mathrm{e}}>150 \mathrm{~cd} / \mathrm{m}^{2}\right.$ and $\eta_{\mathrm{c}}>0.5$ $\mathrm{cd} / \mathrm{A}$ ) required for portable full-color flat displays [31]. Herein, from a costeffective perspective, a conceptual approach to doping of specific organo$\mathrm{Sm}^{3 p}$ complex into PVK for the solution-processed WPLED is provided. On one hand, the blue-light of PVK could smoothly be color-compensated with $\mathrm{Sm}^{3 \mathrm{p}_{-}}$ centered orange-light toward the direct white-light production [17]. Moreover, the doping system endows PVK-assisted good hole-transporting and excellent physical properties [32]. Importantly, its single-component and solutionprocessed WPLED with a significantly simplified device structure, can be expected, which characteristic of white-light stability and cost-effectiveness, should give a new avenue for portable full-color flat displays [31].

\footnotetext{
* Corresponding author. School of Chemical Engineering, Shaanxi Key Laboratory of Degradable Medical Materials, Northwest University, Xi'an, 710069, Shaanxi, China.

** Corresponding author.

E-mail addresses: Ivxq@nwu.edu.cn (X. Lü), fgr@stumail.nwu.edu.cn (G. Fu).

${ }^{1}$ These authors contributed equally to the study. https://doi.org/10.1016/j.jlumin.2020.117054
} 


\section{Experimental}

The information of starting materials and characterization methods was depicted in Electronic Supporting Information (ESI). The pyrazolone ligand Htba-PMP was synthesized from the nucleophilic replacement reaction of 1phenyl-3-methyl-pyrazolone-5 (PMP) and tert-butylacetyl chloride in the presences of $\mathrm{Ca}(\mathrm{OH})_{2}$ and $\mathrm{Ba}(\mathrm{OH})_{2}$ as the literature [12]. The ancillary ligand 5Br-2,2'-bpy (5-Br-2, $2^{\circ}$-bipyridine) was obtained from the Stille coupling reaction [33] between 2, 5-dibromopyridine and 2-(tributylstannyl)pyridine in the presence of $\mathrm{Pd}\left(\mathrm{PPh}_{3}\right)_{4}(0)$.

\subsection{Synthesis of the binary tris-pyrazolate- $\mathrm{Sm}^{3 \mathrm{~b}}$ complex [Sm(tba- $\left.P M P)_{3}\left(5-B r-2,2^{0}-b p y\right)\right](1)$}

To a stirred $\mathrm{MeOH}$ solution $(20 \mathrm{~mL})$ containing the pyrazolone ligand HtbaPMP $(0.6 \mathrm{mmol}, 0.164 \mathrm{~g})$, an equimolar amount of anhydrous $\mathrm{NaOH}(0.6 \mathrm{mmol}$, $0.024 \mathrm{~g})$ was added, and the resultant mixture was reacted at room temperature for $3 \mathrm{~h}$. Another $\mathrm{MeOH}$ solution $\left(15 \mathrm{~mL}\right.$ ) containing $\mathrm{SmCl}_{3} \cdot 6 \mathrm{H}_{2} \mathrm{O}$ $(0.2 \mathrm{mmol}, 0.073 \mathrm{~g})$ and $\mathbf{5}-\mathbf{B r}-\mathbf{2}, \mathbf{2}^{\prime}$-bpy $(0.2 \mathrm{mmol}, 0.047 \mathrm{~g})$ was added, and the resulting mixture was refluxed under a $\mathrm{N}_{2}$ atmosphere for another $3 \mathrm{~h}$. After cooling to room temperature, the obtained clear solution was filtered, and left to stand for several days to afford the microcrystalline product. For complex $\left[\mathrm{Sm}(\mathrm{tba}-\mathrm{PMP})_{3}(5-\mathrm{Br}-\right.$

2,2 ${ }^{0}$-bpy)] (1): Yield: $0.163 \mathrm{~g}, 68 \%$. Anal. Calcd for $\mathrm{C}_{58} \mathrm{H}_{64} \mathrm{~N}_{8} \mathrm{O}_{6} \mathrm{BrSm}: \mathrm{C}, 58.08 ; \mathrm{H}$, 5.38; N, 9.34\%. Found: C, 58.01; H, 5.42; N, 9.38\%. FT-IR (KBr, $\left.\mathrm{cm}^{1}\right): 2953(\mathrm{w})$, $2361(w), 1636(w), 1609(s), 1593(s), 1582(s), 1533(w), 1489(s), 1437(m)$, $1395(w), 1368(m), 1314(w), 1275(w), 1229(w), 1074(m), 1022(w), 1003$ $(\mathrm{m}), 908(\mathrm{w}), 841(\mathrm{w}), 810(\mathrm{w}), 789(\mathrm{w}), 752(\mathrm{vs}), 692(\mathrm{~m}), 650(\mathrm{~m}), 631(\mathrm{w})$, 598 (w), 511 (w). ESI- MS (in MeCN) m/z: $1199.33(100 \%),[M]^{p}$. The synthesis and characterization of the other two referenced complexes [Gd(tba$\left.\mathrm{PMP})_{3}\left(5-\mathrm{Br}-2,2^{0}-\mathrm{bpy}\right)\right](\mathbf{2})$ and [La(tba-PMP $)_{3}\left(5-\mathrm{Br}-2,2^{0}-\right.$ bpy $\left.)\right](3)$ are described in the Electronic Supporting Information.

\subsection{Synthesis of PVK@1 films blending from PVK and complex 1 with different} mass ratios

To a stirred toluene solution $(30 \mathrm{~mL}$ ) containing the commercial PVK $\left(\mathrm{M}_{\mathrm{w}} 1 / 4 \mathrm{~N} \quad 10^{4} \mathrm{~g} / \mathrm{mol} ; \mathrm{PDI} 1 / 41.5\right)$ and complex 1 with a stipulated mass ratio (wt/wt; 10:1 or 10:2.5) was added, and the resultant mixture was continuously stirred at $45 \mathrm{C}$ overnight. After cooling to room temperature, the mixture was spin-coated at $3000 \mathrm{rpm}$ on a clean quartz slide, and then dried in air. The almost similar film thickness of $90 \mathrm{~nm}$ was measured by ellipsometry through collecting data every 5 from 65 to 75 and fitted using a Cauchy film on a gold

Scheme 1. Synthetic scheme of the pyrazolone-typed ligand Htba-PMP, the ancillary ligan model. For PVK@1 films (wt/wt; 10:1 or 10:2.5): Yield: 95\% (10:1); 98\% (10:2.5). Representative FT-IR (KBr, cm $\left.{ }^{1}\right)$ : $3060(\mathrm{w}), 3043(\mathrm{w}), 2972(\mathrm{w}), 2930$ $(\mathrm{w}), 2904(\mathrm{w}), 1622(\mathrm{~m}), 1618(\mathrm{~m}), 1598(\mathrm{~m}), 1584(\mathrm{~m}), 1485$ (s), 1453 (vs), 1408 (w), $1404(w), 1396(w), 1370(w), 1333(s), 1325(s), 1259(w), 1236(m)$, $1226(\mathrm{~s}), 1158(\mathrm{~s}), 1125(\mathrm{~m}), 1076(\mathrm{~m}), 1066(\mathrm{~m}), 1058(\mathrm{~m}), 1027(\mathrm{~m}), 1003(\mathrm{~m})$, $965(w), 926(w), 897(w), 844(w), 812(w), 745(s), 721(s), 697(w), 679(w)$, $672(w), 660(w), 648(w), 626(w), 618(w), 606(w), 563(w), 509(w), 475(w)$.

\subsection{WPLEDs' fabrication and characterization}

Using the synthesized PVK@1 film (10:1,wt/wt) with the straightforward solid-state white-light as the emitting layer, its single- component WPLED configured with ITO/PEDOT:PSS (40 nm)/PVK@1 (90 nm)/TPBi (30 nm)/LiF (1 $\mathrm{nm}) / \mathrm{Al}(100 \mathrm{~nm})$ was fabricated through a typically solution-processed procedure. In these materials, ITO (indium tin oxide) was the coated glass substrate, and PEDOT:PSS (poly(3,4ethylenedioxythiophene):poly(styrenesulfonate)) functions as the holeinjecting material. TPBi (1, 3, 5-tris(2- $N$-phenylbenzimidazolyl)) was used to facilitate the electron-transporting ability in the WPLED. The details of the
WPLED's fabrication and testing are depicted in the Electronic Supporting Information.

\section{Results and discussion}

3.1. Synthesis, characterization, photophysical and electrochemical properties of the binary tris-pyrazolate-Sm3p complex 1

As shown in Scheme 1, through the reaction of $\mathrm{SmCl}_{3} \cdot 6 \mathrm{H}_{2} \mathrm{O}, \mathbf{5}-\mathbf{B r}-\mathbf{2 , 2}$ '-bpy and the pyrazolone ligand Htba-PMP treated with an equimolar amount of anhydrous $\mathrm{NaOH}$, the binary tris-pyrazolate- $\mathrm{Sm}^{3 p}$ complex $\left[\mathrm{Sm}(\text { tba-PMP })_{3}(5-\right.$ $\mathrm{Br}-2,2^{0}$-bpy)] (1) was self-assembled in a receptive yield of $68 \%$. For reference, the other complexes [Gd(tba- PMP $)_{3}\left(5-B r-2,2^{0} \text {-bpy)] (2) and [La(tba-PMP) }\right)_{3}(5-$ $\left.\left.\mathrm{Br}-2,2^{0}-\mathrm{bpy}\right)\right](3)$ were obtained from the same way as complex [Sm(tba$\left.\mathrm{PMP})_{3}\left(5-\mathrm{Br}-2,2^{0}-\mathrm{bpy}\right)\right]$ (1) except that $\mathrm{GdCl}_{3} \cdot 6 \mathrm{H}_{2} \mathrm{O}(0.2 \mathrm{mmol} ; 0.074 \mathrm{~g})$ or $\mathrm{LaCl}_{3} \cdot 6 \mathrm{H}_{2} \mathrm{O}(0.2 \mathrm{mmol} ; 0.071 \mathrm{~g})$ while not $\mathrm{SmCl}_{3} \cdot 6 \mathrm{H}_{2} \mathrm{O}(0.2 \mathrm{mmol}, 0.073 \mathrm{~g})$ was used, respectively.

The three binary tris-pyrazolate- $\mathrm{Ln}^{3 b}$ complexes 1-3 soluble in common organic solvents, were well characterized by EA, FT-IR, ${ }^{1} \mathrm{H}$ NMR and ESI-MS. Especially in the ${ }^{1} \mathrm{H}$ NMR spectrum of the anti-ferromagnetic [La(tba-PMP) $)_{3}(5-$

$\mathrm{Br}-2,2^{0}$-bpy)] (3), the combined proton resonances $\left(\delta \frac{1}{4} 8.82-0.96 \mathrm{ppm}\right)$ of both the deprotonated ligand (tba- PMP) and the ancillary ligand $\mathbf{5 - B r - 2 , 2}$ 'bpy in a stipulated molar ratio of $3: 1$, confirm its desirable binary trispyrazolate-La ${ }^{3 b}$ component [34]. Moreover, the absence of the originally tautomerism-enolic $1 / 4 \mathrm{C}-\mathrm{OH}$ proton signal $(\delta 1 / 414.19 \mathrm{ppm})$ of the Htba-PMP ligand should be arisen from the $\mathrm{La}^{3 \mathrm{~b}}$-coordination. Furthermore, the ESI-MS result of the complexes 1-3 exhibit a strong mass peak at $m / z 1199.33$ for [Sm (tba-PMP) $)_{3}\left(5-\mathrm{Br}-2,2^{0}-\right.$ bpy)] (1), 1207.34 for [Gd(tba-PMP) ${ }_{3}\left(5-\mathrm{Br}-2,2^{0}\right.$-bpy)] (2) or 1188.32 for [ $\left.\mathrm{La}(\mathrm{tba}-\mathrm{PMP})_{3}\left(5-\mathrm{Br}-2,2^{0}-\mathrm{bpy}\right)\right]$ (3) assigned to the major species $[\mathrm{M} \mathrm{H}]^{b}$, respectively. These observations further verify that every binary trispyrazolate-La ${ }^{3 \mathrm{~b}}$ species of the complexes $\mathbf{1 - 3}$ is stable in the respective solution.

The photophysical property of the complexes 1-2 were explored in dilute MeCN solution at room temperature and $77 \mathrm{~K}$, respectively, and summarized in Figs. 1 and 2 and 1S. As shown in Fig. 1S, the similar ligands-based absorption bands (251-253, 270-273 and 314-317 nm) of the complexes 1-2 are observed, where the significantly broadened UV-visible range (200-420 $\mathbf{n m}$ ) relative to those $(<350 \mathrm{~nm}$ ) of the two (Htba-PMP and 5-Br-2,2'-bpy) free ligands, should be contributed from the enhanced $\pi$-conjugation upon $\operatorname{Ln}^{3 p_{-}}$ coordination. Upon photo- excitation $\left(\lambda_{\text {ex }} 1 / 4340 \mathrm{~nm}\right)$ for [Sm(tba-PMP) $)_{3}(5-\mathrm{Br}$ $2,2^{0}$-bpy)] (1), as shown in Fig. 1 , the strong $\mathrm{Sm}^{3 \mathrm{~b}}$-centered characteristic emissions ( $569 \mathrm{~nm}\left({ }^{4} \mathrm{G} 5 / 2 \rightarrow{ }^{6} \mathrm{H} 5 / 2\right.$ transition), $609 \mathrm{~nm}\left({ }^{4} \mathrm{G} 5 / 2 \rightarrow{ }^{6} \mathrm{H} 7 / 2\right.$ transition), -Br-2,2'-bpy and their binary tris-pyrazolate- $\mathrm{Ln}^{3 \mathrm{~b}}$ complex [ $\mathrm{Ln}(\mathrm{tba}-$

$651 \mathrm{~nm}\left({ }^{4} \mathrm{G} 5 / 2 \rightarrow{ }^{6} \mathrm{H} 9 / 2\right.$ transition) and $706 \mathrm{~nm}\left({ }^{4} \mathrm{G}_{5} / 2 \rightarrow{ }^{6} \mathrm{H} 11 / 2\right.$ transition $\left.)\right)$ and the weak while detectable emission peaking at $\lambda_{\mathrm{em}} 1 / 4422 \mathrm{~nm}$ are concurrently observed, exhibiting a bright orange-light with a $\mathrm{CIE}$ 


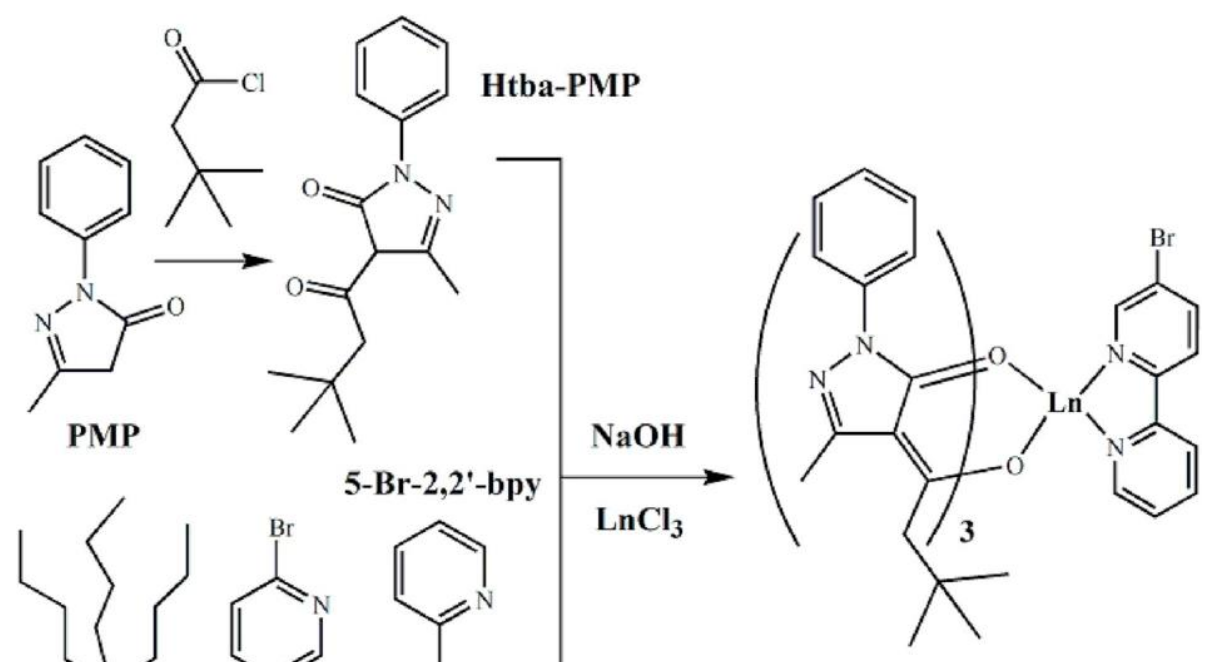

[Ln(tba-PMP) $)_{3}\left(5-B r-2,2^{\prime}-\right.$ bpy $\left.)\right]$

PMP) $)_{3}\left(5-B r-2,2^{0}-\right.$ bpy $\left.)\right](\operatorname{Ln} 1 / 4$ Sm, 1; Ln 1/4 Gd, 2 or Ln 1/4 La, 3).

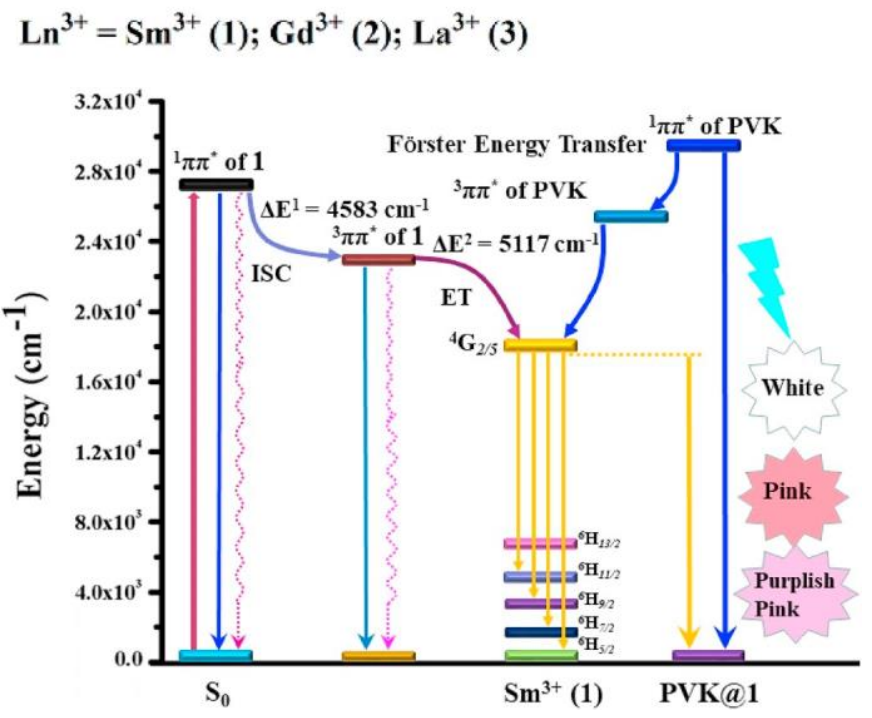

Fig. 2. The schematic energy level diagram and possible energy transfer processes for the complex $\left[\mathrm{Sm}(\mathrm{tba}-\mathrm{PMP})_{3}\left(5-\mathrm{Br}-2,2^{0}-\mathrm{bpy}\right)\right](\mathbf{1})$ and its blending PVK@1 films.

Fig. 1. The excitation and visible emission spectra of complexes [Sm(tba- $\mathrm{PMP})_{3}\left(5-\mathrm{Br}-2,2^{\mathrm{O}}-\right.$ bpy)] (1) and [Gd(tba-PMP) $\left.{ }_{3}\left(5-B r-2,2^{0}-b p y\right)\right](2)$ in dilute MeCN solution $\left(110^{5} \mathrm{M}\right)$ at room temperature or $77 \mathrm{~K}$.

(Commission International De L'Eclairage) chromatic coordinate $x 1 / 40.553$ and y $1 / 40.345$. For the dual-emitting complex 1 , the ligands-based residual visible $\left(\lambda_{\text {em } 1 / 4} 422 \mathrm{~nm}\right)$ emission should be assigned to the intra- ligands $\pi-\pi^{*}$ transition, and the hyper-sensitive peak at $651 \mathrm{~nm}$ from ${ }^{4} \mathrm{G}_{5 / 2} \rightarrow{ }^{6} \mathrm{H}_{9 / 2}$ transition should be resulted from its low molecular symmetry [35]. Moreover, its dualemissive nature can further be confirmed with the lifetimes-decayed combination of ligands-based fluorescence ( $\tau 1 / 41.46 \mathrm{~ns} ; \lambda_{\mathrm{em}} 1 / 4422 \mathrm{~nm}$ ) and $\mathrm{Sm}^{3 \mathrm{~b}}$-centered phosphorescence $\left(\tau 1 / 450 \mu\right.$ s of $\mathrm{Sm}^{3 \mathrm{~b}}$-based ${ }^{6} \mathrm{H}_{9 / 2} ; \lambda_{\mathrm{em}} 1 / 4651 \mathrm{~nm}$ ) from the same chromophores.

To address the sensitization mechanism of the $\mathrm{Sm}^{3 \mathrm{~b}}$-based complex 1 , the emissive property of the $\mathrm{Gd}^{3 \mathrm{~b}}$-based complex $\mathbf{2}$ as the reference in solution at room temperature or $77 \mathrm{~K}$ was also examined. For the $\mathrm{Gd}^{3 \mathrm{~b}}$ - based complex $\mathbf{2}$, contrary to the ligands-based fluorescence ( $\lambda_{\mathrm{em}} 1 / 4422 \mathrm{~nm}$ and $\left.\tau \frac{1}{4} 2.49 \mathrm{~ns}\right)$ at room temperature, it exhibits the typical 0-

0 transition phosphorescence $\left(\lambda_{\mathrm{em}} 1 / 4434 \mathrm{~nm}\right.$ and $\left.\tau \frac{1}{4} 11.4 \mu \mathrm{s}\right)$ at $77 \mathrm{~K}$, from which, the triplet $\left({ }^{3} \pi-\pi^{*}\right)$ energy level of $23,041 \mathrm{~cm}{ }^{1}$ is reasonably estimated. Considering the UV-visible absorbance edge at $\lambda_{\mathrm{ab}}{ }^{1 / 4} 362 \mathrm{~nm}$, the singlet $\left({ }^{1} \pi^{-}\right.$

$\pi^{*}$ ) energy level of $27,624 \mathrm{~cm}^{1}$ is obtained. As shown in Fig. 2, the slightly smaller energy gap $\Delta E^{1}\left(4583 \mathrm{~cm}^{1}\right)$ between the ${ }^{1} \pi-\pi^{*}$ and ${ }^{3} \pi-\pi^{*}$ energy levels, endows a relatively effective ISC process according to the Reinhoudt's empirical rule [36]. Therefore, the residual ligands-based emission $\left(\lambda_{\mathrm{em}} 1 / 4422\right.$ $\mathrm{nm})$, together with the $\mathrm{Sm}^{3 \mathrm{~b}}$-centered sensitization through the large enough energy gap $\Delta E^{2}\left(5117 \mathrm{~cm}{ }^{1} ;{ }^{3} \pi-\pi^{*}-{ }^{4} G_{5 / 2}\right)$ between the ligands-based ${ }^{3} \pi-\pi^{*}$ energy and the first excited state ${ }^{4} \mathrm{G}_{5 / 2}\left(17,924 \mathrm{~cm}^{1}\right)$ of $\mathrm{Sm}^{3 \mathrm{p}}$ ion regulated with the Latva's empirical rule [37], should be the reason to the dual emissions for the complex 1. Meanwhile, just through that efficient sensitization with the strong absorption followed by the ${ }^{1} \pi-\pi^{*} \rightarrow{ }^{3} \pi-\pi^{*}$ ISC and the effective ${ }^{3} \pi-\pi^{*}$ $\rightarrow{ }^{4} \mathrm{G}_{5 / 2}$ transition of $\mathrm{Sm}^{3 \mathrm{~b}}$ ion, the complex 1 characteristic of the $\mathrm{Sm}^{3 p_{-}}$ centered orange-light, gives rise to a quantum efficiency $\left(\Phi^{\mathrm{L}} \mathrm{sm}\right)$ of $5.2 \%$. Noticeably, although the complex 1 shows a significantly lower photoluminescent output than those (up to $30 \%$ ) of tris-pyrazolate- $\mathrm{Tb}^{3 \mathrm{~b}}$-complex analogues [7-9] due to the fact that the ${ }^{4} \mathrm{G}_{5 / 2}-{ }^{6} \mathrm{H}_{5 / 2}$ energy gap of $\mathrm{Sm}^{3 b}$ ion is relatively small $\left(\sim 7400 \mathrm{~cm}^{1}\right)$, which favors non-radiative decay processes [38], its $\Phi^{\mathrm{L}} \mathrm{sm}(5.2 \%)$ is receptive among previously reported organo-Sm${ }^{3 b_{\text {}}}$-complexes [20-28] for orange-light OLEDs.

To further elucidate the electrochemical behavior of the $\mathrm{Sm}^{3 \mathrm{~b}}$-based complex 1, its cyclic voltammogram (CV) experiment was explored. As shown in Fig. $2 \mathrm{~S}$, based on an oxidation potential of $0.72 \mathrm{~V}$ versus $\mathrm{Fc}^{\mathrm{b}} / \mathrm{Fc}$, the HOMO level of the complex 1 is estimated to be $5.48 \mathrm{eV}$. By checking its lower-energy wavelength (362 nm, also Fig. 1S) at the UV-visible absorbance edge, the 
energy gap $E_{\mathrm{g}}$ of $3.43 \mathrm{eV}$ can also reasonably estimated. Therefore, the LUMO level of $2.05 \mathrm{eV}$ for the complex $\mathbf{1}$ is actually calculated.

\subsection{Color-tuning photophysical properties of PVK@1 films blended from PVK and complex 1}

In consideration of the hole-transport-included good physical properties [32] of the blue-emitting PVK, the single-component hybrid films PVK@1 were easily obtained from the physical mixing of the commercial PVK and the complex 1 with different mass ratios (wt/wt; 10:1 and 10:2.5). The PXRD patterns (Fig. 3S) of these two PVK@1 films with different doping contents just exhibit the PVK-based amorphous peaks, indicating the low-concentration and homogeneous distribution of the complexes $\mathbf{1}$ into the polymeric PVK. Moreover, the TG analysis result (Fig. 4S) of the representative PVK@1 film (wt/wt; 10:1) shows the significantly improved thermal stability, given that a higher decomposition temperature interval of $448-460 \mathrm{C}$ than that $(282 \mathrm{C}$ ) of the complex 1. In addition, the determined $T_{\mathrm{g}}$ of the representative PVK@1 film (wt/wt; 10:1) can be up to $190 \mathrm{C}$, from which, it is of particular opportunity to utilize the PVK@1 film (wt/wt; 10:1) as the ideal emitting layer for flexible WPLEDs.

The concentration-relative (wt/wt; $10: 1$ and 10:2.5) photo- luminescent properties of the PVK@1 films at room temperature were explored, and summarized in Fig. 3. Importantly, the dichromatic- integration colors of these two PVK@1 films are strictly enslaved to the excitation wavelength. Based on the significant overlap (also Fig. 1S) between the emission of the PVK host and the absorption of the complex

1 within the 280-320 nm range, $\lambda_{\text {ex }} 1 / 4280-320 \mathrm{~nm}$ with every $10 \mathrm{~nm}$ step-size should be used as the suitable excitation regime to realize the
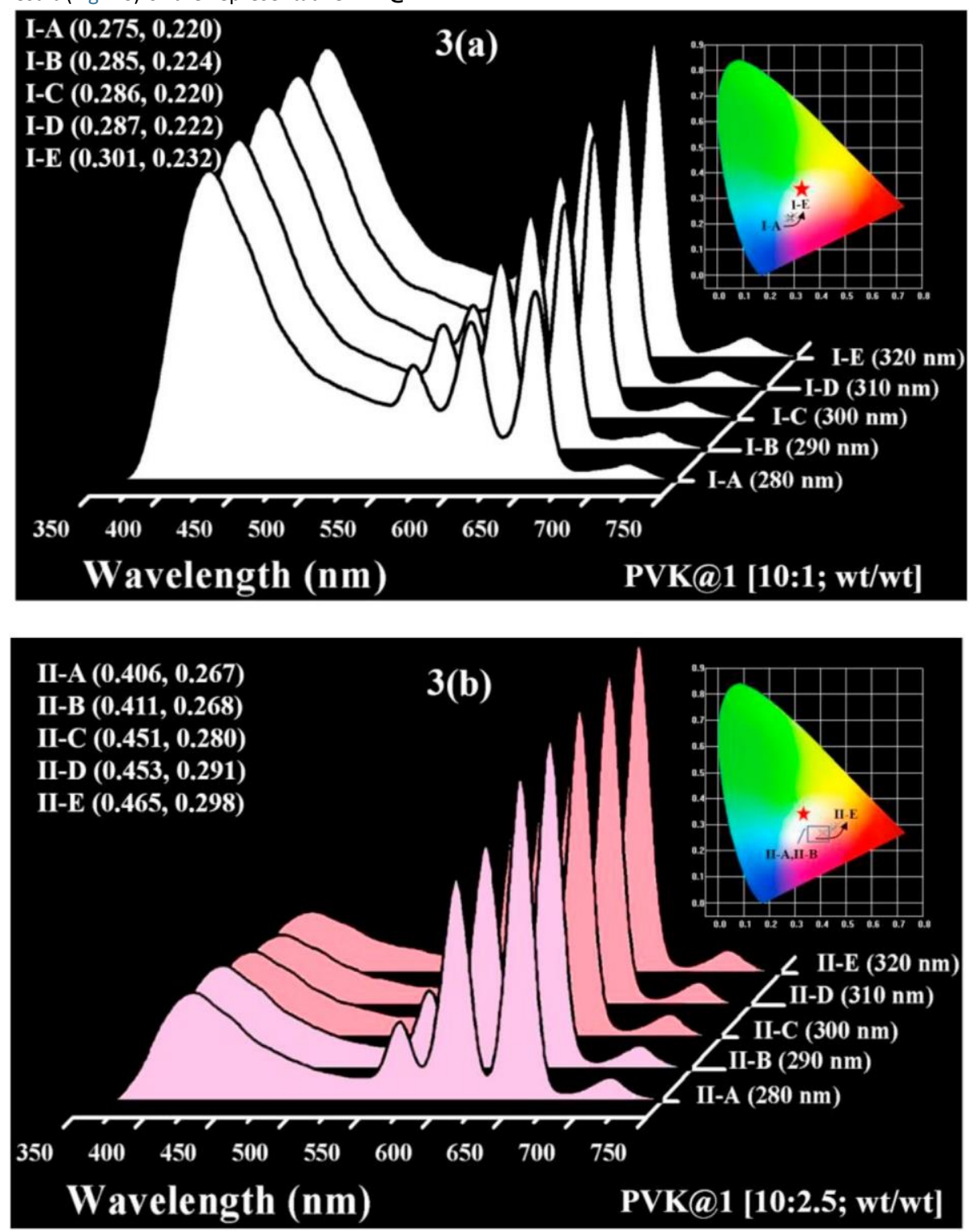

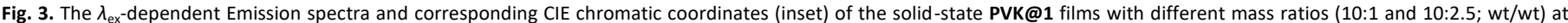
room temperature. 

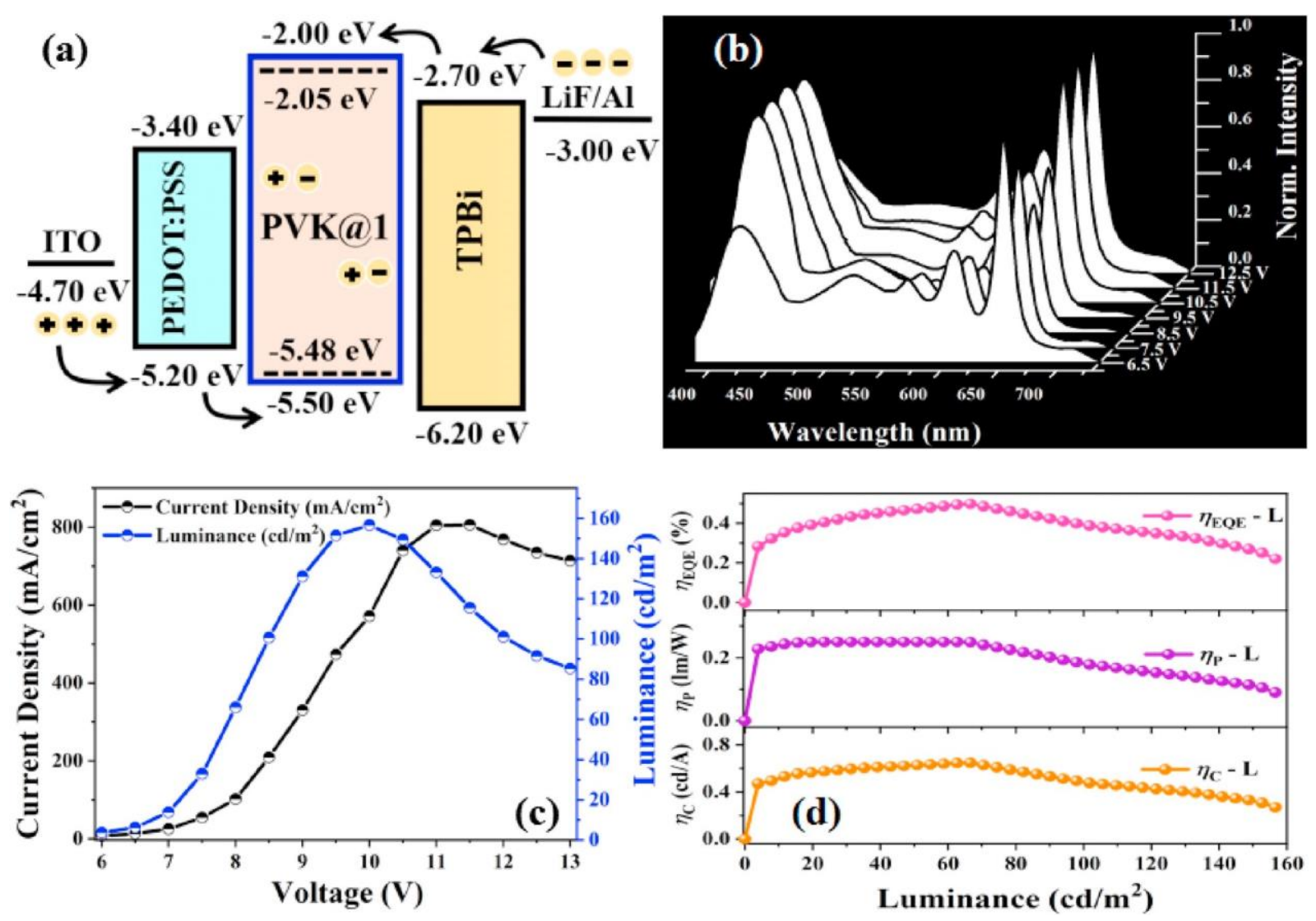

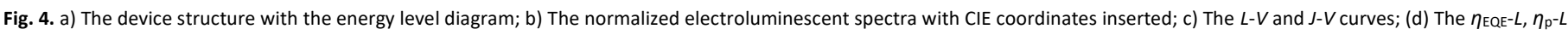
and $\eta_{c}-L$ curves for the WPLED based on the PVK@1 film (10:1; wt/wt).

dichromatic-modulated white-light especially in motivation with an effective Forster energy transfer [ $€ 12$ ] from the PVK host to the complex

1. Under the feeding mass ratio of $10: 1$, photo-excitation $\left(\lambda_{\mathrm{ex}} 1 / 4\right.$

280-320 nm) renders the PVK@1 film the simultaneous emissions (Fig. 3a) of the PVK-based blue-light $(422 \mathrm{~nm})$ and the $\mathrm{Sm}^{3 \mathrm{~b}}$-centered orange-light. Interestingly, with the increase of the excitation wavelengths within the 280$320 \mathrm{~nm}$ region toward the maximum excitation wavelength $(340 \mathrm{~nm})$ of the complex $\mathbf{1}$, the orange-to-blue relative intensity ratio increases, correspondingly, indicating that effective Forster $€$ energy transfer [12] from the PVK host to the complex 1 actually occurs. Besides all the resultant colorcoordinates (I-A-E; $x$ 1/4 $0.275-0.301$, y $1 / 40.220-0.232$ ) located within the desirable white-light regime, their white-light quality of the dichromaticmodulation is reflected from the CCTs of 1762-2328 K and the CRIs within 7791. Clearly, the warm-white-lights endowed with the CCTs (1762-2328 K) beyond the 2500-6500 $\mathrm{K}$ region, should be resulted from the typically dichromatic [7] while not trichromatric modulation for the PVK@1 film (10:1; wt/wt). Nonetheless, among the stable white-lights with little colorcoordinates shifts $(|\Delta x|<0.03,|\Delta y|<0.02)$, the obtained quantum yield up to $5.8 \%$ for the best white-light point I-E $\left(\lambda_{\text {ex }} 1 / 4320 \mathrm{~nm} ; x \frac{1}{4} 0.301, y 1 \frac{1}{4} 0.232\right.$, CCT of $2328 \mathrm{~K}$ and $\mathrm{CRI}$ of 91 ) is at the top level within previously reported organo-Sm ${ }^{3 \mathrm{~b}}$-complexes [20-25] or organo-Sm ${ }^{3 \mathrm{~b}}$-doping systems [26-29] for orange-light OLEDs/PLEDs. Meanwhile, the 32 ns lifetime of PVK-incorporated blue-light $\left(\lambda_{\text {em }} 1 / 4422 \mathrm{~nm}\right)$ and the Sm ${ }^{3 \mathrm{~b}}$-decayed $\left(\lambda_{\mathrm{em}} 1 / 4651 \mathrm{~nm}\right)$ lifetime of 216 $\mu \mathrm{s}$, confirm that the optimal white-light for the PVK@1 film (10:1; wt/wt) upon $\lambda_{\text {ex }} 1 / 4320 \mathrm{~nm}$ should unambiguously originate from both fluorescence and phosphorescence dichromatic incorporation.

Further with the increase of the $\mathrm{Sm}^{3 \mathrm{~b}}$-doping content up to 10:2.5 (wt/wt), it leads to the pronounced $\mathrm{Sm}^{3 \mathrm{~b}}$-centered orange-light. As shown in Fig. $3 \mathrm{~b}$, the relatively higher $\mathrm{Sm}^{3 \mathrm{~b}}$-doping content $(10: 2.5$; wt/ wt) renders the integrated colors significantly deviated from the white- light regime, exhibiting

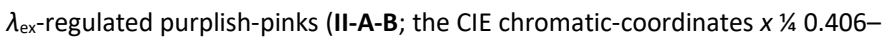

$0.411, y \frac{1}{4} 0.267-0.268$; the CCTs of 2231-2332 K and the CRIs of 89-90 with $\lambda_{\text {ex }} 1 / 4280-290 \mathrm{~nm}$ ) to pink colors (II-C-E; the CIE chromatic-coordinates $x 1 / 4$ $0.451-0.465, y 1 / 4$

$0.280-0.298$; the CCTs of $2233-2668 \mathrm{~K}$ and the CRIs of $87-90$ with $\lambda_{\text {ex }} 1 / 4300-$ $320 \mathrm{~nm}$ ) also highly stabilized. It is worth noting that the residual blue-light species of the PVK@1 film (10:2.5; wt/wt) decay with an almost constant lifetime (36 ns) to that (32 ns) of the PVK@1 film (10:1; wt/wt), suggesting the excess amount (either 10:2.5 or 10:1) of the PVK host with saturation [12] of the dichromatic balance in the PVK@1 films.

\subsection{Device performance of the single-component WPLED based on the PVK@1 film (10:1,wt/wt)}

Considering the direct solid-state white-lights of the 1@PVK film (10:1; $w t / w t)$, its single-component solution-processed WPLED was fabricated, and the device performance was summarized in Fig. 4. On one hand, the deeper LUMO level ( $2.05 \mathrm{eV}$ ) of the complex 1 than that ( $2.00 \mathrm{eV}$ ) of PVK, and its shallower LUMO level ( $5.48 \mathrm{eV}$ ) than that ( $5.50 \mathrm{eV})$ of PVK, suggest the suitability of the PVK host when doped with the complex 1 . Meanwhile, according to the proposed energy level diagram for the WPLED shown in Fig. $4 \mathrm{a}$, the two HOMO levels ( $5.50^{\sim}-5.48 \mathrm{eV}$ ) of PVK and the complex 1 are well between those ( $\left.6.20^{\sim}-5.20 \mathrm{eV}\right)$ of TPBi and PEDOT:PSS. Therefore, the injected electrons and holes could be trapped and recombined within the whit- light-emitting species PVK@1 (10:1, wt/wt).

As expected, the normalized electroluminescent spectra (Fig. 4b) of the WPLED based on the PVK@1 (10:1, wt/wt) also exhibit the simultaneous emissions of PVK-based blue-light $\left(\lambda_{\mathrm{em}} 1 / 4422 \mathrm{~nm}\right)$ and Sm ${ }^{3 \mathrm{~b}}$ - centered $\left(\lambda_{\mathrm{em}} 1 / 4651\right.$ $\mathrm{nm}$ ) orange-light throughout the whole applied bias voltage range (6.0-12.5 $\mathrm{V}$ ), leading to the integrated colors (CIE chromatic coordinates $x 1 / 40.260$ $0.353, y 1 / 40.211-0.313$ ) well within the desired white-light regime. However, in contrast to the $\lambda_{\text {ex }}$-relative monotonous increasing (also Fig. 3a) of the 
orange-to-blue relative intensity ratio, the electroluminescent spectra are highly dependent on the applied bias voltages, where owing to the carriertrapping mechanism during the electric-driven process, the orange-to-blue relative intensity ratio increases first and insistently decreases after $10.0 \mathrm{~V}$. As shown in Fig. $4 \mathrm{c}$, after the turn-on voltage $\left(V_{\text {on }}\right.$ at $\left.1 \mathrm{~cd} / \mathrm{m}^{2}\right)$ of $6.0 \mathrm{~V}$, the WPLED keeps stable in the 6.0-10.0 V range, both the luminance $\left(L, \mathrm{~cd} / \mathrm{m}^{2}\right)$ and the current density $\left(J, \mathrm{~mA} / \mathrm{cm}^{2}\right)$ monotonously increase, and a $L^{\operatorname{Max}}$ of $157 \mathrm{~cd} / \mathrm{m}^{2}$ is achieved at $10.0 \mathrm{~V}$ with a current density of $570 \mathrm{~mA} / \mathrm{cm}^{2}$. Under the stable premise, as shown in Fig. $4 \mathrm{~d}$, with the an increase of the applied bias voltage or the luminance, all the efficiencies $\left(\eta_{c}, \eta_{p}\right.$, and $\left.\eta_{\text {EQEE }}\right)$ increase first and insistently decrease with the $\eta^{\operatorname{Max}}{ }_{c}$ of $0.65 \mathrm{~cd} / \mathrm{A}$, the $\eta^{\mathrm{Max}}{ }_{\mathrm{p}}$ of $0.25 \mathrm{~lm} / \mathrm{W}$ and the $\eta^{\mathrm{Max}}{ }_{\text {EQE }}$ of $0.5 \%$ at $8.0 \mathrm{~V}\left(L 1 / 466 \mathrm{~cd} / \mathrm{m}^{2}\right)$, respectively. Upon the applied bias voltage up to $10.0 \mathrm{~V}$, the heavy efficiency-roll-offs with the $\eta_{\mathrm{c}} 1 / 40.27 \mathrm{~cd} / \mathrm{A}$, the $\eta_{\mathrm{p}} 1 / 40.09 \mathrm{Im} / \mathrm{W}$ and the $\eta_{\text {EQE }} 1 / 40.22 \%$ of the WPLED are observed, which should mainly be attributed to $\mathrm{Sm}^{3 \mathrm{~b}}$-centered phosphorescence lifetime being too long [26]. Nonetheless, the single-component WPLED's performance reforms with almost three times efficiencies (the $\eta^{\mathrm{Max}}{ }_{\mathrm{c}}$ of $0.65 \mathrm{~cd} / \mathrm{A}$, the $\eta^{\mathrm{Max}}{ }_{\mathrm{p}}$ of 0.25 $\mathrm{Im} / \mathrm{W}$ and the $\eta^{\mathrm{Max}}$ EQE $0.5 \%$ ) to those of previously organo-Sm ${ }^{3 \mathrm{p}}$-based WOLEDs [30], which together with the white-light-emitting stability, is satisfactory enough to the requirements for portable full-color flat displays [31]. Further increasing the applied bias voltage $(>10.0 \mathrm{~V})$, its significantly inferior performance should be attributed to the aging of the WPLED.

\section{Conclusions}

In summary, through the self-assembly of the pyrazolone ligand Htba-PMP, $\mathrm{SmCl}_{3} \cdot 6 \mathrm{H}_{2} \mathrm{O}$ and the ancillary ligand $5-\mathbf{B r}-\mathbf{2}, \mathbf{2}^{\prime}$-bpy, the binary tris-pyrazolate$\mathrm{Sm}^{3 \mathrm{~b}}$ complex [Sm(tba-PMP) $3\left(5-\mathrm{Br}-2,2^{0}-\mathrm{bpy}\right)$ ] (1) with efficient orange-light was obtained. When doping of the complex 1 into the PVK host, exhibit the dichromatic color-tunable (white-light or purple-light) characters. Further utilizing the PVK@1 film (10:1; wt/wt) with the straightforward white-light as the emitting layer, its single- component WPLED gives the good electroluminescent performance $\left(L^{\mathrm{Max}}\right.$ of $157 \mathrm{~cd} / \mathrm{m}^{2}, \eta^{\mathrm{Max}}{ }_{\mathrm{c}}$ of $0.65 \mathrm{~cd} / \mathrm{A}$ and the white-light-emitting stability), which, satisfactory enough for portable fullcolor flat displays, could be further improved after the following optimizations of both the organo-Sm ${ }^{3 p}$ complex structure and the WPLED's procedure.

\section{Declaration of competing interest}

We promise that this work is original, unpublished even not being considered elsewhere, and we declare no conflict of interest.

\section{Acknowledgements}

This work is funded by the National Natural Science Foundation of China (21373160, 21173165), the MOE Laboratory of Bioinorganic and Synthetic Chemistry, the State Key Laboratory of Structural Chemistry (2019) and the Graduate Innovation and Creativity Fund (YZZ17127) of Northwest University in China.

\section{Appendix A. Supplementary data}

Supplementary data to this article can be found online at https://doi. org/10.1016/j.jlumin.2020.117054.

\section{References}

1. Zhang, Y. F.; Xu, Z.; Zhang, F. J.; Wang, Y.; Zhao, S. L., White organic light emitting device with dyestuff DCJTB mended in polymer. Spectroscopy and Spectral Analysis 2008, 28 (4), 760-762.

2. Watanabe, K.; Sakamoto, T.; Taguchi, M.; Fujiki, M.; Nakano, T., A chiral pi-stacked vinyl polymer emitting white circularly polarized light. Chem. Commun. 2011, 47 (39), 10996-10998.
3. Wang, R.; Peng, J.; Qiu, F.; Yang, Y. L., Enhanced white-light emission from multiple fluorophores encapsulated in a single layer of diblock copolymer micelles. Chem. Commun. 2011, 47, 2787-2789

4. Prakash, A.; Katiyar, M., White polymer light emitting diode using blend of fluorescent polymers. 16th International Workshop on Physics of Semiconductor Devices 2012, 8549.

5. $\quad$ Park, J. J.; Park, T. J.; Jeon, W. S.; Kim, S. Y.; Lee, Y. K.; Jang, J.; Kwon, J. H., White Polymeric Light-Emitting Diodes Based on Doping of an Orange Ir Complex in a Fluorene Blue Polymer Host. Mol. Cryst. Liq. Cryst. 2009, 498, 290-297.

6. $\quad$ Park, J. J.; Park, T. J.; Jeon, W. S.; Kim, S. Y.; Lee, Y. K.; Jang, J.; Kwon, J. H., White polymeric light-emitting diodes based on doping of an orange Ir complex in a fluorene blue polymer. Idw '07: Proceedings of the 14th International Display Workshops, Vols 1-3 2007, 1033-1036.

7. Nicolai, H. T.; Hof, A. J.; Blom, P. W. M., Charge transport in white light-emitting polymers. Organic Optoelectronics and Photonics $l i$ 2006, 6192.

8. Nicolai, H. T.; Hof, A.; Blom, P. W. M., Device Physics of White Polymer Light-Emitting Diodes. Adv. Funct. Mater. 2012, 22 (10), 2040-2047. 9. Li, B. N.; Liu, L.; Fu, G. R.; Zhang, Z.; Li, H. Y.; Lu, X.; Wong, W. K.; Jones, R. A., Color-tunable to direct white-light and application for white polymer light emitting diode (WPLED) of organo-Eu3+- and organo-Tb3+doping polymer. J. Lumin. 2017, 192, 1089-1095.

10. Shen, F. Z.; He, F.; Lu, D.; Xie, Z. Q.; Xie, W. J.; Ma, Y. G.; Hu, B., Bright and colour stable white polymer light-emitting diodes. Semiconductor Science and Technology 2006, 21 (2), L16-L19.

11. Kim, C.; Gwon, Y. J.; Kim, J.; Lee, T. S., Synthesis of fluorescent conjugated polymer nanoparticles and their immobilization on a substrate for white light emission. Polym Chem-Uk 2018, 9 (48), 5671-5679.

12. Amin, G.; Zaman, S.; Zainelabdin, A.; Nur, O.; Willander, M., ZnO nanorods-polymer hybrid white light emitting diode grown on a disposable paper substrate. Physica Status Solidi-Rapid Research Letters 2011, 5 (2), 7173.

13. Taudt, C.; Baselt, T.; Oreski, G.; Hirschl, C.; Koch, E.; Hartmann, P., Cross-linking characterization of polymers based on their optical dispersion utilizing a white-light interferometer. Optical Measurement Systems for Industrial Inspection Ix 2015, 9525.

14. Song, H. J.; Shin, G. J.; Choi, K. H.; Lee, S.; Moon, D. K., White polymer light emitting diode materials introducing dendritic quinoxaline derivative: Synthesis, optical and electroluminescent properties. Synthetic Metals 2014, 190, 1-7.

15. Lee, H. K.; Kim, T. H.; Park, J. H.; Kim, J. K.; Park, O. O., Whitelight-emitting diodes using miscible polymer blend doped with phosphorescent dye. Organic Electronics 2011, 12 (6), 891-896. 16. Kim, J. H.; Song, W. S.; Yang, H., Color-converting bilayered composite plate of quantum-dot-polymer for high-color rendering white light-emitting diode. Opt. Lett. 2013, 38 (15), 2885-2888.

17. Kassamakov, I.; Ojala, K.; Salmia, A.; Haeggstrom, E.; Aaltonen, J.; Huber, A.; Saarikko, H.; Osterberg, M.; Oinonen, M., Characterization of dents and grooves on polymer films using scanning white light interferometry. Optical Micro- and Nanometrology in Microsystems Technology 2006, 6188.

18. Inoue, A.; Hosokawa, T.; Haishi, M.; Ohtani, N., 4(dicyanomethylene)-2-methyl-6-(p-dimethylaminostyryl)-4H-pyran (DCM)doping density dependence of luminescence spectra and white emission in polymer light-emitting diodes. Physica Status Solidi C - Current Topics in Solid State Physics, Vol 6, No 1 2009, 6 (1), 334-337.

19. Hu, B.; Yao, C.; Huang, X. R., Designing of the White-Light Emission from a Single-Polymer System: Quantum Theoretical Study. Polymer Science Series A 2011, 53 (11), 1097-1105.

20. Fan, L. M.; Fan, W. L.; Li, B.; Zhao, X.; Zhang, X. T., W-shaped 1,3-di(2,4-dicarboxyphenyl)benzene based lanthanide coordination polymers with tunable white light emission. New J. Chem. 2016, 40 (12), 10440-10446.

21. da Silva, M. A. T.; Thomazini, E. F.; Albertini, M.; Renzi, W.; Franchello, F.; Dias, I. F. L.; Duarte, J. L.; Pocas, L. C.; Lourenco, S. A., Characterization of digital textile printing and polymer blend (PFODMP:P3HT) for application in manufacture of organic diodes emitting white light - WOLEDS. Optical Materials 2016, 62, 119-131.

22. Chen, M. X.; Sun, R. Y.; Ye, Y. C.; Tang, H. J.; Dong, X. Y.; Yan, J. L.; Wang, K. M.; Zhou, Q.; Wang, Z. L., Application of a novel red-emitting 
cationic iridium(III) coordination polymer in warm white light-emitting diodes. Optical Materials 2018, 76, 141-146.

23. Wang, R.; Peng, J.; Qiu, F.; Yang, Y. L.; Xie, Z. Y., Simultaneous blue, green, and red emission from diblock copolymer micellar films: a new approach to white-light emission. Chem. Commun. 2009, (44), 6723-6725. 24. Hrma, M.; Sichova, K.; Svoboda, J.; Vohlidal, J., Assembling of bis(tpy)fluorenes with $\mathrm{Zn2}+$ and Fe2+ ions into metallo-supramolecular polymers with highly efficient white-light emission. Polymer 2017, 122, 22 33.

25. Chitara, B.; Bhat, S. V.; Vivekchand, S. R. C.; Gomathi, A.; Rao, C. N. R., White-light sources based on composites of GaN nanocrystals with conducting polymers and nanophosphors. Solid State Communications 2008, 147 (9-10), 409-413.

26. Cheng, G.; Fei, T.; Zhao, Y.; Ma, Y. G.; Liu, S. Y., White

phosphorescent polymer light-emitting devices based on a wide band-gap polymer derived from 3,6-carbazole and tetraphenylsilane. Organic Electronics 2010, 11 (3), 498-502.

27. Chen, S. A.; Chang, E. C.; Chuang, K. R.; Chao, C. I.; Wei, P. K.; Fann, W. S., Conjugated polymer blends as emitting layer for white light led. Abstr. Pap. Am. Chem. Soc. 1998, 215, U392-U392.

28. Zhen, H. Y.; Xu, W.; King, W.; Chen, Q. L.; Xu, Y. H.; Jiang, J. X. Peng, J. B.; Cao, Y., White-light emission from a single polymer with singlet and triplet chromophores on the backbone. Macromol. Rapid Commun. 2006, 27 (24), 2095-2100.

29. Zhang, T. H.; Gong, Z. C.; Que, L., A white-light source operated polymer-based micromachined Fabry-Perot chemo/biosensor. 2009 4th leee International Conference on Nano/Micro Engineered and Molecular Systems, Vols 1 and 2 2009, 181-184.

30. Willander, M.; Nur, O.; Zaman, S.; Zainelabdin, A.; Bano, N.; Hussain, I., Zinc oxide nanorods/polymer hybrid heterojunctions for white light emitting diodes. J. Phys. D: Appl. Phys. 2011, 44 (22).

31. Wang, Z. W.; Gao, D. Z.; Ma, X. J.; Meng, J., White-Light Interferometry for Measuring Fuel Pressure in Icf Polymer-Microsphere Targets. Fusion Sci. Technol. 2014, 66 (3), 432-437.

32. Wang, B. Z.; Zhang, X. P.; Liu, H. M., White-light-emitting diode based on a single-layer polymer. Aip Advances 2013, 3 (5).

33. Tian, L. L.; Zhang, W.; Yang, B.; Lu, P.; Zhang, M.; Lu, D.; Ma, Y. G.; Shen, J. C., Zinc(II)-induced color-tunable fluorescence emission in the piconjugated polymers composed of the bipyridine unit: A way to get whitelight emission. J. Phys. Chem. B 2005, 109 (15), 6944-6947.

34. Tang, K. C.; Tseng, S. R.; Li, W. S.; Meng, H. F.; Horng, S. F.; Hsu, C. S., Broad band and white phosphorescent polymer light-emitting diodes in multilayer structure. Synthetic Metals 2008, 158 (7), 287-291.

35. Sun, C.; Zhang, Y.; Sun, K.; Reckmeier, C.; Zhang, T. Q.; Zhang, X. Y.; Zhao, J.; Wu, C. F.; Yu, W. W.; Rogach, A. L., Combination of carbon dot and polymer dot phosphors for white light-emitting diodes. Nanoscale 2015, 7 (28), 12045-12050.

36. $\quad$ Roberts, R. J.; Le, D.; Leznoff, D. B., Color-Tunable and WhiteLight Luminescence in Lanthanide Dicyanoaurate Coordination Polymers. Inorg. Chem. 2017, 56 (14), 7948-7959.

37. Qin, L. J.; Zhu, Y. C.; Yang, H.; Ding, L.; Sun, F.; Shi, M.; Yang, S. P., White-light phosphorescence from binary coordination polymer nanoparticles. Mater. Chem. Phys. 2013, 139 (2-3), 345-349.

38. Ovens, J. S.; Christensen, P. R.; Leznoff, D. B., Designing Tunable White-Light Emission from an Aurophilic Cu-I/Au-I Coordination Polymer with Thioether Ligands. Chemistry-a European Journal 2016, 22 (24), 82348239.

39. Niu, Y. H.; Liu, M. S.; Ka, J. W.; Bardeker, J.; Zin, M. T.;

Schofield, R.; Chi, Y.; Jen, A. K. Y., Crosslinkable hole-transport layer on conducting polymer for high-efficiency white polymer light-emitting diodes. Adv. Mater. 2007, 19 (2), 300-+.

40. Niu, W. Y.; Sun, J. W.; Yan, P. F.; Li, Y. X.; An, G. H.; Li, G. M., 2D I-Di-toluoyl-tartaric acid Lanthanide Coordination Polymers: Toward Singlecomponent White-Light and NIR Luminescent Materials. Chemistry-an Asian Journal 2016, 11 (4), 555-560.

41. Nam, G. H.; Park, I. K., CdSe Quantum dot-conducting polymer hybrid structure for Phosphor-free white light-emitting diodes. Journal of the Korean Physical Society 2015, 66 (5), 785-789.

42. Meng, L. C.; Lou, Z. D.; Yang, S. Y.; Hou, Y. B.; Teng, F.; Liu, X. J.; $\mathrm{Li}, \mathrm{Y}$. B., White organic light-emitting diodes based on a combined electromer and monomer emission in doubly-doped polymers. Chinese Physics B 2012, 21 (8). 